\title{
Debates sobre os conceitos de direita e a pertinência de uma tipologia dual para classificação dos partidos brasileiros
}

\author{
Mariani Ferri de Holanda ${ }^{1}$
}

\section{Resumo}

Esse trabalho se debruça sobre o debate conceitual dos fundamentos epistemológicos da ideologia de direita, de acordo com a literatura internacional e brasileira, na forma de um ensaio bibliográfico. Pretende-se a partir disso, analisar um fenômeno latente na realidade políticoinstitucional do país, mas que ainda não se corporificou na bibliografia especializada e talvez nem tenha sido percebido pelos próprios agentes envolvidos nesse processo, que seria: a diferenciação programática dos partidos políticos de direita no Brasil. Com esse exame, procuramos avançar no estudo dos conceitos sobre a Direita e aprofundar o debate sobre esse espectro ideológico no país, indicando a existência de diferenças consideráveis entre os correligionários dessa ideologia; elucidadas pela validade de uma agrupação binomial: partidos do "neoliberalismo pragmático" e partidos de uma direita mais recente, que aqui chamamos de "conservadorismo não-elitizado". Mobilizamos os seguintes partidos para ilustrar a validade dessa classificação: Partido da Social Democracia Brasileira (PSDB), Democratas (DEM), Partido Progressista (PP) como representantes do "neoliberalismo pragmático" e Partido Renovador Trabalhista Brasileiro (PRTB), Partido da República (PR) e Partido Social Cristão (PSC) como representantes do "conservadorismo não-elitizado".

Palavras-chave: Partidos Políticos; Direita; Conservadorismo; Liberalismo; Direita no Brasil.

\section{Abstract}

This paper focuses on the conceptual debate of the epistemological foundations of right-wing ideology, according to international and Brazilian literature, in the form of a bibliographic essay. It is intended to analyze a latent phenomenon in the political-institutional reality in Brazil, but which has not yet been embodied in the specialized bibliography and may not even have been perceived by the agents involved in this process, namely: the programmatic differentiation of political parties right wing in Brazil. With this examination, I seek to advance in the study of the concepts of the Right and to deepen the debate on this ideological spectrum in the country, indicating the existence of considerable differences among the coreligionists

\footnotetext{
${ }^{1}$ Mestranda em Ciência Política no Instituto de Estudos Sociais e Políticos da Universidade do Estado do Rio de Janeiro (IESP/UERJ). Esse trabalho é parte da monografia defendida como pré-requisito para obtenção do título de bacharel em Ciência Política pela Universidade Federal do Estado do Rio de Janeiro (UNIRIO). Agradeço às críticas e sugestões dos avaliadores anônimos da Leviathan.
} 
of this ideology; elucidated by the validity of a binomial grouping: parties of "pragmatic neoliberalism" and parties of a more recent right, which I will call here "non-elitist conservatism." I mobilized the following parties to illustrate the validity of this classification: Brazilian Social Democracy Party (PSDB), Democrats (DEM), Progressive Party (PP) as representatives of "pragmatic neoliberalism" and the Brazilian Labor Renovation Party (PRTB), Republic's Party (PR) and Christian Social Party (PSC) as representatives of "non-elitist conservatism".

Key-words: Political Parties; Right-wing; Conservatives; Liberalism; Rightwing in Brazil.

\section{Introdução}

Esse trabalho se debruça sobre o debate conceitual dos fundamentos epistemológicos da ideologia de direita, de acordo com a literatura internacional e brasileira, na forma de um ensaio bibliográfico. Pretende-se a partir disso, analisar um fenômeno latente na realidade político-institucional do país, mas que ainda não se corporificou na bibliografia especializada e talvez nem tenha sido percebido pelos próprios agentes envolvidos nesse processo, que seria: a diferenciação programática dos partidos políticos de direita no Brasil. Com esse exame, procuramos avançar no estudo dos conceitos sobre a Direita e aprofundar o debate sobre essa parte do espectro ideológico no país, indicando a existência de diferenças consideráveis entre os correligionários dessa ideologia; elucidadas pela validade de uma agrupação binomial: partidos do "neoliberalismo pragmático" e partidos de uma direita mais recente, que aqui chamamos de "conservadorismo não-elitizado". Mobilizamos os seguintes partidos para ilustrar a validade dessa classificação: Partido da Social Democracia Brasileira (PSDB), Democratas (DEM), Partido Progressista (PP) como representantes do "neoliberalismo pragmático" e Partido Renovador Trabalhista Brasileiro (PRTB), Partido da República (PR) e Partido Social Cristão (PSC) como representantes do "conservadorismo não-elitizado".

Trazendo à luz da discussão uma tipologia sobre uma divisão presente na Direita, aponta-se para a existência de um novo ator no cenário político: o "conservadorismo não-elitizado". Ao contrário do que se entende aqui por "neoliberalismo pragmático" - herdeiro do capital político de partidos que apoiaram a 
Ditadura Militar (no caso brasileiro) e identificado com as políticas neoliberais no plano econômico e social dos anos 1980 e 1990 (reconfiguração mundial da identidade de Direita) -, o "conservadorismo não-elitizado", além de não ter o ônus dessas associações, aceitaria, pragmaticamente, as resoluções sociais implementadas pelos governos de esquerda, coabitando em suas bases aliadas - fenômeno matizado por um moralismo conservador, muitas vezes de viés religioso e com sustentáculo retórico e eleitoral nas classes menos abastadas e economicamente emergentes (caráter nãoelitizado $)^{2}$.

\section{Noções sobre o conceito de direita na literatura internacional e sua aplicação aos partidos brasileiros}

Não há democracia sem partidos políticos. Eles estão presentes desde mobilizados uma noção mínima de democracia - que se encerra na competição eleitoral - como intermediadores entre as demandas do eleitorado e as possibilidades e pretensões dos políticos; em outros termos, são importantes como "atalhos informacionais" para a decisão do voto (Downs, 1999); mas também são cruciais para o entendimento do fazer político enquanto deliberação e debate de projetos de sociedade que representam demandas de coletividades. Mesmo as leituras que desacreditam a democracia da forma como a conhecemos - liberal - reivindicam a força dos partidos políticos para a organização da busca de uma nova utopia ou de resistência enquanto contra-hegemonia. Cabe nota que, concomitante ao advento moderno da Democracia, os partidos políticos tornaram-se atores indissociáveis da existência desse tipo de regime (Manin, 1995).

Ainda que a contemporaneidade seja marcada por um movimento inegável (uma tendência mundial) de perda de identificação do eleitorado e esvaziamento das identidades dos partidos políticos (Piven, 1992), não se minora a importância dos partidos na qualidade de instituições essenciais para a manutenção da ordem democrática, nem se atenua a discussão sobre a pertinência de uma classificação ideológica num contínuo esquerda-direita. As diferenças ideológicas entre os partidos

\footnotetext{
${ }^{2}$ Cabe ressaltar que o aspecto não-elitizado da base social do "conservadorismo não-elitizado" ficará restrito ao plano da teoria nesse trabalho.
} 
continuam sendo utilizadas como variável independente, desde uma leitura sobre o padrão das coalizões até uma avaliação das políticas públicas implementadas. No Brasil, essa discussão contempla ainda a problemática de alocarmos as ideologias partidárias no espectro esquerda-direita, sem irromper na tentação da transposição direta de indicadores criados para realidades externas.

A díade esquerda-direita tem sua origem atribuída à localização espacial dos membros da Assembleia Nacional Constituinte Francesa durante a convocação dos Estados Gerais em 1789, quando os delegados ligados à aristocracia, à defesa da monarquia e ao tradicionalismo, sentavam-se à direita do recinto, enquanto os representantes partidários de uma reformulação da ordem política e social e simpatizantes da revolução que se instaurava, dispunham-se à esquerda. Ao longo da Revolução Francesa esse ordenamento persistiu nas ocasiões de reconfiguração da Assembleia Nacional. Essa divisão permaneceu e foi abarcando novas significações. No século XIX, a dicotomia refletiu-se em sinônimo de liberalismo (progressismo) e conservadorismo (tradicionalismo). No final do século XIX e início do século XX, a perspectiva marxista inclui no debate público pautas anti-capitalista e de classe (operária) na agenda da esquerda. Somam-se a esse revigoramento da esquerda nesse período, os debates reformistas da social-democracia e as interpretações trazidas pela Revolução de 1917. Dos anos 1930 a 1950, o keynesianismo, as políticas welfaristas e o estatismo autoritário da União Soviética, reformulam a díade a partir da oposição Estado forte (esquerda) x liberdade no mercado (direita). Essa polarização se mantém como uma das mais pertinentes chaves analíticas para situar a discussão esquerdadireita atualmente; com a novidade de ser recolocada nos marcos redistributivistas (esquerda) e neoliberal (direita).

Norberto Bobbio (2011) em seu livro “Direita e esquerda: Razões e significados de uma distinção política" desenvolve um dos parâmetros mais reconhecidos para o estabelecimento dessa discussão. Revisitando várias díades propostas, Bobbio afirma que a igualdade-desigualdade é o único critério presente em todas as dicotomias aventadas, podendo ser entendida, portanto, como um princípio fundador, resistente à usura do tempo e à dissolução a que estiveram sujeitos os outros critérios. Dessa 
forma, uma refundação da díade esquerda-direita faz premente uma "reorganização dos critérios derivados "do valor fixo da igualdade" ou do "caráter crucial da igualdade como valor" (2011, p.94). Com base nesse pressuposto, o autor investiga o componente relativo da igualdade: "igualdade entre quem, em relação a que e sob quais critérios?" (ibidem: 97). Tomando essas referências, Bobbio conclui que o que melhor caracterizaria os movimentos entendidos como de esquerda é o igualitarismo: "tendência, de um lado, a exaltar mais o que faz os homens iguais do que o que os faz desiguais, e de outro, em termos práticos, a favorecer as políticas que objetivam tornar mais iguais os desiguais" (ibidem: 110). Os agrupamentos tidos como de direita determinam-se pela defesa de uma desigualdade natural entre os indivíduos; sendo a tentativa de construção de uma igualdade social tida por uma farsa. A esquerda estaria, portanto, preocupada com a viabilidade da execução de uma igualdade material, ao passo que a direita estaria interessada em garantir e estender uma igualdade formal (todos são iguais perante a lei); em outras palavras, seguindo essa concepção, a esquerda se associa à igualdade e a direita à liberdade.

A direita, acompanhando a interpretação de Bobbio, ao assumir uma postura de aceitação apriorística das diferenças, carrega posições sociais conservadoras. Ao aceitar que as hierarquias entre os indivíduos são naturais, elas tornam-se inalienáveis e passam a ser causa e efeito do modo pelo qual a sociedade se organiza. Por conseguinte, essa concepção de sociabilidade passa a ser vinculada ao conservadorismo.

O Conservadorismo não se apresenta, nem se pretende, uma corrente de pensamento formulada a partir de pressupostos teóricos rígidos e sistematizados. Ele decorre e se caracteriza por ser um movimento reativo às alterações no sistema político existente e nos modos de funcionamento das instituições sociais. 0 reconhecimento da existência dessa carga emotiva na defesa da manutenção de uma ordem anterior na tradição (Bonazzi, 2010 apud Bobbio; Matteuci; Pasquino, 2010) imbui o pensamento político conservador de uma preocupação intensa com a moralidade social.

Paulo Mercadante (1980) teorizando sobre a "A consciência conservadora no Brasil" argumenta que: 


\begin{abstract}
Em geral, não contém a mentalidade conservadora, por si própria, predisposição teorizante. Parte de uma pragmática de que não cumpre divagar sobre as situações em que se encontram os homens naturalmente ajustados [...] Mas que o ataque ideológico de um grupo social, a pronunciar uma nova era, ou que represente interesse de grupos sociais ascendentes é que provoca no espírito conservador os túrbidos receios quanto à segurança do poder, dando margem a determinadas reações teóricas. (Mercadante, 1980, p. 245).
\end{abstract}

Os pressupostos da moralidade conservadora são sistematizados e expostos por Russel Kirk (2005) em uma obra que se tornou canônica dessa linha de pensamento, “A Mentalidade Conservadora" de 1953. Nela, o autor lista 10 princípios basilares ${ }^{3}$ dessa corrente:

1) Ordem Moral - Um conservador acredita que há uma duradoura ordem moral que é feita pelos homens e que os homens são feitos dela; em outras palavras, que a natureza humana é constante e que verdades morais são permanentes. Ordem significa harmonia e há, portanto, dois aspectos dessa ordem: a ordem interior da alma e a ordem exterior do Estado. Isto implica dizer que as questões sociais para os conservadores também competem ao escrutínio da moralidade privada, sendo a sociedade valorada conforme a correspondência das ações humanas com a duradoura ordem moral. Uma sociedade na qual homens e mulheres são governados por um forte senso de certo e errado e por convicções pessoais de honra e justiça, será uma boa sociedade - independente das instituições políticas que forem utilizadas. Entretanto, uma sociedade na qual homens e mulheres sejam moralmente fluidos, ignorem as normas, e pretendam governar para a satisfação de suas vontades, será uma má sociedade - à revelia do quanto de liberdades políticas se possa contemplar.

2) Costume, convenção e continuidade - Conservadores aderem ao costume, à convenção e à continuidade porque eles "preferem o diabo conhecido ao diabo que eles não conhecem". Ordem, justiça e liberdade são os resultados artificiais de um longo processo de reflexão e sacrifício. Por isso, a continuidade, a

3 Ver também: KIRK, Russell. Ten Conservative Principles. Disponível em: <http://www.kirkcenter.org/index.php/detail/ten-conservative-principles/>. Acesso em: 08 de maio de 2016. 
essência vital da sociedade, não deve ser interrompida. Endossando Burke, eles concordam que quando a mudança se faz necessária, ela precisa ser prudente gradual e discriminada - nunca com finalidades imprecisas.

3) Princípio da Prescrição - Conservadores enfatizam a importância da prescrição - do estabelecimento imemorial da moralidade e da perspectiva social. Dessa forma, é pouco provável que a modernidade avance mais nesse sentido; sendo inclusive perigoso pesar todas as questões na racionalidade do julgamento privado.

4) Princípio da Prudência - Todas as medidas políticas deveriam ser pensadas a partir de suas prováveis consequências de longo prazo, não apenas por sua vantagem temporária e por sua popularidade.

5) Princípio da Variedade - Para a preservação de uma diversidade saudável, em qualquer sociedade, é necessária a manutenção de hierarquias e classes, diferenças na condição material e vários tipos de desigualdade. As únicas formas de igualdade admitidas são a do Juízo Final e a perante um tribunal. Outras tentativas de forjar a igualdade, levam à estagnação social, pois, uma vez que as diferenças naturais e institucionais são destruídas, a sociedade fica passível da intervenção de qualquer ação tirana para criar novas formas (necessárias) de desigualdade.

6) Princípio da Imperfectibilidade - A natureza humana padece de graves falhas irremediáveis, sendo o homem imperfeito e o intuito de se criar uma ordem social perfeita impossível. Tudo o que podemos esperar razoavelmente, no entanto, é uma sociedade sofrivelmente ordenada, justa e livre, na qual alguns males, desajustes e desprazeres permanecerão. Buscar a utopia da perfeição é terminar num desastre, porque nós não somos capazes de coisas perfeitas.

7) Liberdade e Propriedade - Liberdade e propriedade estão intimamente ligadas. A propriedade privada foi um poderoso instrumento para ensinar aos homens motivos para a integridade, para apoiar a cultura geral, para elevar a humanidade acima do mero trabalho penoso e para proporcionar lazer para pensar e liberdade para agir. O conservador reconhece que a posse da propriedade imprime certos deveres ao possuidor; que os aceita de bom grado, 
pois ao obedecê-los, ele está assegurando a liberdade conferida por sua propriedade a si próprio e aos demais, já que todos os proprietários compartilham essa convicção.

8) Comunidades voluntárias - Em uma comunidade genuína, as decisões que afetam mais diretamente a vida dos cidadãos são feitas local e voluntariamente. Mas quando essas funções passam a ser uma usurpação de autoridade centralizada (grande influência do Estado), a comunidade fica em grave perigo.

9) Poder e paixões humanas - Concebendo a natureza humana como uma mistura de bem e mal, o conservador não deposita sua confiança em mera benevolência. Restrições constitucionais, checks and balances, aplicação adequadas das disposições legislativas são usados como instrumentos de liberdade e ordem porque o conservador percebe a necessidade de restrições prudentes sobre o poder das paixões humanas para limitar e equilibrar o poder político entre a anarquia ou a tirania. Um governo justo mantém uma tensão saudável entre as reivindicações de autoridade e as reivindicações de liberdade.

10) Mudança - O pensamento conservador entende que permanência e mudança devem ser reconhecidas e reconciliadas em uma sociedade vigorosa. O conservador não se opõe ao progresso social, embora ele duvide que haja uma linearidade evolutiva do progresso. Quando uma sociedade está progredindo em alguns aspectos, geralmente ela está em declínio em outros. O conservador, em suma, fundamenta-se num progressismo parcimonioso; ele se opõe ao culto do progresso, cujos adeptos acreditam que tudo que é novo é necessariamente superior. A mudança é essencial para o corpo social, segundo as razões conservadoras tal como ela é essencial para o corpo humano. Um corpo que deixou de renovar-se começou a morrer. Mas se esse corpo é para ser vigoroso, a mudança deve ocorrer de forma regular, harmonizando-se com a forma e natureza do corpo; caso contrário, a mudança produz um crescimento monstruoso, um câncer, que devora seu hospedeiro. 
Não se autoproclamando nem uma religião nem uma ideologia (Kirk, 2005), o pensamento conservador se caracteriza por um conjunto de valores morais balizados por uma estrutura ordenada e hierarquizada de concepção da realidade social. Essa mesma conformação é encontrada no pensamento religioso do cristianismo. Por conseguinte, não é estranho a associação que os partidos com comportamento programático religioso têm com os preceitos conservadores; o que nesse trabalho pode ser ilustrado pela chamada "família de partidos" (Ennser, 2010) do "conservadorismo não-elitizado", como demonstram os casos do Partido da República (PR), Partido Renovador Trabalhista Brasileiro (PRTB) e Partido Social Cristão (PSC).

O Partido da República (PR) é produto da fusão, ocorrida em 26 de outubro de 2006, entre Partido Liberal (PL) e o Partido da Reedificação da Ordem Nacional (PRONA) para alcance da cláusula de barreira de $5 \%$ vigente a época. Segundo a definição do próprio partido, "valores e princípios que constituíam o PL e o PRONA foram mesclados" (PR, 2016). O liberalismo (social) do primeiro e o nacionalismo (autoritário) do segundo combinaram-se para conformar a orientação ideológica do novo partido, de viés marcadamente conservador. De acordo com seu Manifesto:

\footnotetext{
Comprometido com o regime democrático, a doutrina proposta pelos republicanos do PR busca a realização do Bem Comum numa sociedade livre, pluralista e participativa. $O$ ideal de liberdade do PR está consignado na reafirmação da "crença na Pessoa livre, titular de direitos naturais e inalienáveis". E este princípio abrange a sociedade como unidade orgânica, a organização Política como fator de administração da sociedade, dirigida ao Bem Comum. Para o Partido da República a pessoa deve ser valorizada na individualidade. Para os estamentos do PR, uma visão ideológica do Estado e da Sociedade faz com que o Homem se fracione, esquecendo sua qualidade de ser concreto, a grandeza de sua origem e de sua missão pessoal. A criação do PR consignou o respeito aos valores naturais como único limite à liberdade individual. A consciência desses valores éticos insere o indivíduo em sua sociedade natural, histórica e humana, permitindo-lhe a plena realização das potencialidades (PR, 2016).
}

A narrativa de busca do bem comum e da externação de potencialidades inatas numa comunidade de homens livres e iguais vem ao encontro dos princípios conservadores postulados por Kirk (2005). À semelhança, a leitura de que "o Estado deve ser o gerador das garantias dos direitos humanos, promotor e guardião do Bem Comum. O Estado institucionaliza o poder com exclusivo objetivo de promover o Bem Social. Só se justifica quando é instrumento para a eliminação de todas as formas de dominação entre os homens" (PR, 2016) conjuga com o (neo)liberalismo de Hayek 
(2010), Mises (2010) e Friedman (1982). Na 54 legislatura (2011-2015), o PR tinha a sexta maior bancada da Câmara dos Deputados com 41 membros e a terceira maior do Senado, junto ao DEM, com 9 membros cada. Logo após sua fundação, o PR ingressou na coalizão de apoio do PT (Amorim Neto, 2011), permanecendo nela até o impeachment de Dilma Rousseff.

O Partido do Renovador Trabalhista Brasileiro (PRTB) provém de membros do extinto Partido Renovador Trabalhista (PTR), que reivindicavam o legado e o ideário político de Fernando Ferrari, com seu "trabalhismo participativo" e anti-getulismo. 0 partido abrigou, em 2000, a candidatura do ainda inelegível, ex-presidente Fernando Collor de Melo à prefeitura de São Paulo. Já em situação regularizada, Collor candidatou-se em 2002 ao governo de Alagoas pelo partido, mas não conseguiu ser eleito. Em 2006, conseguiu eleger-se senador pelo PRTB, tendo migrado para o PTB no mesmo dia de sua posse. Em 2010 e 2014, o partido lançou a candidatura de seu presidente Levy Fidelix à Presidência da República. Seu desempenho eleitoral foi ínfimo. Na última legislatura, o PRTB teve 2 deputados federais e nenhum senador.

O Partido Social Cristão (PSC) é fundado em maio de 1985 em decorrência do cenário de multipartidarismo promovido pelo início da abertura democrática; mas o partido só recebe seu registro em 1990. Nesse mesmo ano, elege o governador de Alagoas Geraldo Bulhões e no ano anterior participa da coligação com o Partido da Reconstrução Nacional (PRN) na eleição presidencial de 1989, ajudando a eleger Fernando Collor de Melo (1990-1992) à Presidência da República. O PSC tem um histórico de lançar candidatos próprios para disputas majoritárias, especialmente as presidenciais. Fato que ocorreu em 1994 com Hermani Fortuna e em 1998 com Sérgio Bueno. Em 2002, coligou-se com o Partido Socialista Brasileiro (PSB) na candidatura de Anthony Garotinho e em 2010, repetiu a tática, dessa vez com o PT na eleição de Dilma Rousseff. Em 2014, o partido voltou a lançar candidato próprio para a disputa do cargo presidencial, com a nomeação de Everaldo Pereira, conhecido por Pastor Everaldo. Seus candidatos tiveram resultados irrisórios nos pleitos citados, mas a opção do partido em disputar uma eleição presidencial aponta para uma postura propositiva e uma preocupação em pautar sua agenda e formar uma imagem para com a opinião 
pública e seu eleitorado. A Doutrina Social Cristã reivindicada pelo partido, consolidouse numa oposição de direita a pautas progressistas e ao governo do PT. Único dos partidos estudados assumidamente de viés religioso, sobretudo evangélico, "o Cristianismo, mais do que uma religião, representa para o PSC um estado de espírito que não segrega, não exclui nem discrimina" (PSC, 2016). Justifica-se, assim, muitas posições conservadoras que o partido defendeu nos últimos anos (Sung, 2015). Na última legislatura, o PSC possuía 17 deputados federais e 1 senador.

Esses partidos conjugam posições políticas e programáticas conservadoras, denotando valores cristãos e assentando suas bases sociais e eleitorais nas classes religiosas menos abastadas e economicamente emergentes, demostrando seu caráter duplamente não-elitizado. Os preceitos do cristianismo preconizam uma hierarquia entre os homens através de virtudes espirituais (fé, amor a Deus) e não de riquezas materiais, enquanto para a Teoria das Elites, há em toda a sociedade uma minoria privilegiada que detém o poder de forma privada, em contraposição há uma maioria desprovida deste; sendo o poder econômico, o poder ideológico e o poder político os tipos mais importantes de exercício do poder (Bobbio, 2010: 385). Os partidos pertencentes à essa classificação, não se configurariam elites em nenhuma das duas acepções, pois: 1) apresentam princípios norteadores não-materiais (religião); 2) alicerçam suas bases sociais em grupos que não possuem protagonismo do controle econômico (classes menos abastadas); 3) configuram hegemonia ideológica da sociedade - religião cristã - mas que tem ou deveria ter um papel secundário como categoria de influência política e; 4) não são atores centrais no jogo político-partidário ${ }^{4}$.

Seguindo nossa hipótese, a moral conservadora não representa nem todo, nem somente, o espectro da direita. Alterações de paradigma ocorridas nas bases ideológicas tanto da esquerda quanto da direita, a partir dos anos 1970, influenciaram sensivelmente seus rumos contemporâneos. A emergência dos governos de Margareth Thatcher (1979) na Grã-Bretanha e de Ronald Reagan (1981) nos Estados Unidos e do

\footnotetext{
${ }^{4}$ Esses pequenos partidos de direita ganharam importância política-partidária nos últimos anos, a partir da reconfiguração de forças do que se convencionou chamar de "centrão". Sobre o tema ver: Munhoz, Sarah Regina. "A atuação do "Centrão" na Assembléia Nacional Constituinte de 1987/1988: dilemas e contradições". Revista Política Hoje, vol. 20, n. 1, 2011. Disponível em: https://periodicos.ufpe.br/revistas/politicahoje/article/viewFile/3816/3120. Acesso em: 20 de maio de 2018.
} 
neoliberalismo significou um marco refundacional da direita (Peirucci, 1999; Alves, 2000). O modelo keynesiano e welfarista, hegemônicos dos anos 1930 aos 1960, começa a se esgotar nos anos 1970. A "direita tradicional", liberal no plano econômico, mas que comungava com uma burocracia estatal garantidora da harmonia social, começa a ceder lugar para um paradigma de Estado mínimo. Os choques do preço do petróleo, as crises financeiras e a queda de crescimento econômico que a Europa e os Estados Unidos enfrentam nessa década são os gargalos conjecturais para a emersão do projeto neoliberal. A mudança de ordem ocorre corroborada pelo esgotamento político do comunismo soviético e pela crise do projeto político e social da socialdemocracia europeia, além da reconfiguração do padrão econômico, com o aprofundamento da globalização financeira que reestruturou os modos de produção e acumulação capitalista. O pensamento de direita que se configura a partir desse panorama é chamado pela literatura de "nova direita" (Oliveira; Benetti, 2014; Gonzáles, 2013; Alves, 2000; Pierucci, 1999); sendo traduzido nesse ensaio pela família de partidos do "neoliberalismo pragmático" com Partido da Social Democracia Brasileira (PSDB), Democratas (DEM) e Partido Progressista (PP).

O Partido da Social Democracia Brasileira (PSDB) surge nos marcos da Assembleia Nacional Constituinte de 1987-88 oriundo de um grupo de dissidentes do Partido do Movimento Democrático Brasileiro (PMDB) capitaneados por lideranças de São Paulo e Minas Gerais, descontentes com o governo Sarney. Originalmente, o PSDB é formado por uma confluência de correntes ideológicas, coexistindo em seu interior: os social-democratas - a tendência majoritária no partido, os liberais/progressistas - ala mais conservadora, os socialistas-democráticos - a corrente mais à esquerda e, finalmente, os democratas-cristãos. A agenda neoliberal ganha, ao longo do tempo, força no discurso e prática do partido, consolidando-se quando Fernando Henrique Cardoso (1994-2002) assume a Presidência (Guiot, 2014).

A valorização da "eficiência", envolvendo uma "ampla reforma do setor público", não deveria abdicar da descentralização de recursos, funções e encargos para os estados e municípios, o que constituiria, segundo eles, a "democratização das decisões". Trata-se, em linha gerais, daquilo que em outros documentos os peessedebistas chamam de "desprivatização do Estado", isto é, do afastamento de interesses privados e corporativos 
incrustados na administração pública em prol de genuínos "mecanismos de controle público", concomitante a uma completa profissionalização e reformulação dos serviços públicos, que visem a sua "racionalização". "Racionalização" essa agregada à lógica da "eficiência" e da "competitividade", própria do mercado, e ao elogio da "eficácia" das associações da sociedade civil na implementação de políticas sociais, pressuposto central do neoliberalismo da terceira via (Guiot, 2014, p.3).

A execução de uma plataforma de governo tecnocrática, na qual "reformas incontornáveis" na máquina pública são colocadas como um paradigma da política de Estado, e a coalizão com o PFL (atual DEM) são considerados marcos para a guinada do PSDB à direita. Apesar de em sua origem, o PSDB autodeclarar-se centro-esquerda (PSDB, 2016), grande parte da literatura que se debruça sobre classificação ideológica dos partidos políticos - Kinzo (1990), Novaes (1994), Figueiredo e Limongi (1999), Fernandes (1995), Rodrigues (2002) e Power (2000) - o identificam por centro. Análises mais recentes, como a de Carreirão (2006) e de Tarouco e Madeira (2013), já o classificam como um partido de direita. Na 54 legislatura (2011-2015), o PSDB representava a terceira maior bancada da Câmara dos Deputados com 54 membros e a segunda maior do Senado Federal com 17 senadores, em igualdade com o Partido dos Trabalhadores (PT). Desde a eleição de 2002, o partido disputou todos os segundos turnos das eleições presidenciais com o PT, nos quais Fernando Henrique Cardoso foi vitorioso nas eleições de 1994 e 1998 em primeiro turno; nas duas ocasiões, com o candidato petista Lula da Silva em segundo. Em 2002, Lula da Silva foi eleito presidente, vencendo o candidato do PSDB, José Serra, e foi reeleito, em 2006, derrotando Geraldo Alckmin. Em 2010, a candidata do PT, Dilma Rousseff, tornou-se presidenta disputando pleito contra o candidato José Serra; e em 2014, foi reeleita vencendo o candidato Aécio Neves.

O Democratas (DEM) é o resultado da refundação, ocorrida em 2006, do antigo Partido da Frente Liberal (PFL), que por sua vez era uma dissidência do antigo Partido Democrático Social (PDS), sucessor direto da Aliança Renovadora Nacional (ARENA) partido sustentáculo da ditadura militar (Kinzo, 1988). Em junho de 1984, houve uma cisão no PDS devido a divergências sobre a sucessão do general Figueiredo. O partido ficou polarizado entre o grupo de apoio a Paulo Maluf, que defendia a continuidade do regime militar e o grupo de apoio a Aureliano Chaves, esgotados com a longevidade da ditadura. Diante do insucesso da indicação do nome do segundo grupo, Marco Maciel, 
Jorge Bornhausen e Guilherme Palmeira, fizeram um acordo com o PMDB apoiando o nome de Tancredo Neves e formando a "Aliança Democrática". Com a vitória de Tancredo Neves na eleição indireta de 1985, o agora PFL passou a ser base do novo governo no Congresso, mesmo com a posse de Sarney (Babireski, 2014).

O PFL fez parte da coalizão de Collor de Melo (1990-1992) e apoiou o PSDB nas disputas eleitorais de 1994 e 1998, fazendo parte de sua coalizão nos dois governos FHC. A passagem para a oposição ocorreu em 2002 com a chegada do PT à Presidência; posição que ocupava até o impeachment de Dilma Rousseff. Desde de sua saída do governo, o PFL enfrentou um paulatino declínio eleitoral (Fleischer, 2007). Da maior bancada na Câmara dos Deputados em 1998 com 105 membros, seu contingente foi reduzido para 84 em 2002, a 65 em 2006, chegando a apenas 43 em 2010. O partido alterou sua nomenclatura para Democratas (DEM) em 2007 como uma estratégia de suas lideranças para renovar o partido e estabelecer uma nova identidade para a organização e, assim, garantir a sua sobrevivência eleitoral. Em 2011, o DEM sofre uma importante dissidência com a criação do Partido Social Democrático (PDS). Deixam a legenda nomes como Gilberto Kassab, então prefeito de São Paulo, Kátia Abreu, senadora pelo Tocantins e líder dos agropecuaristas, e Raimundo Colombo, governador de Santa Catarina (Babireski, 2014). Ainda assim, o DEM teve na 54 legislatura (20112015), quinta maior bancada da Câmara dos Deputados com 43 membros e a terceira maior do Senado, com 9 membros, empatado com o Partido da República (PR). Por suas origens e seu posicionamento político, o DEM é classificado como um partido de direita (Kinzo, 1990; Novaes, 1994; Figueiredo; Limongi, 1999; Fernandes, 1995; Rodrigues, 2002; Power, 2000; Carreirão, 2006; Tarouco; Madeira, 2013).

O Partido Progressista (PP), à semelhança do PFL/DEM, origina-se de um desmembramento do extinto Partido Democrático Social (PDS), herdeiro político da ARENA. Em abril de 1993, o PDS funde-se ao Partido Democrata Cristão (PDC), formando o Partido Progressista Reformador (PPR). Em 1996, o PPR incorpora o Partido Popular (PP), alterando sua nomenclatura para Partido Progressista Brasileiro (PPB). Em 2003, o partido muda novamente, passando para Partido Progressista (PP). Para além de seu histórico autoritário, o PP é considerado um partido de direita por grande parte 
da literatura (Kinzo, 1990; Novaes, 1994; Figueiredo; Limongi, 1999; Fernandes, 1995; Rodrigues, 2002; Power, 2000; Carreirão, 2006; Tarouco; Madeira, 2013) e por sua própria descrição como "o reagrupamento de forças estaduais de perfil moderado e conservador" (PP, 2016). Apesar de ser um partido de lideranças estaduais, a exemplo de Paulo Maluf em São Paulo e Ana Amélia no Rio Grande do Sul e até 2015, Jair Bolsonaro no Rio de Janeiro, após seus primeiros anos, o PP alterou sua estratégia para ocupação de postos nos escalões governamentais, diminuindo o foco na disputa por cargos majoritários e ocupando o papel de base de apoio (Mayer \& Babireski, 2013). Desde o primeiro mandato de FHC até o segundo mandato de Dilma Rousseff (19942014), o partido constituiu-se initerruptamente como governo, exceto nos dois primeiros anos do primeiro governo Lula (2003-2005) (Amorim Neto, 2011: 89-90). Na $54^{\circ}$ legislatura, o PP possuía a $4^{\circ}$ maior bancada da Câmara com 44 deputados federais e a $4^{\circ}$ do Senado com 8 senadores.

Esse "neoliberalismo pragmático" caracteriza-se pelo enfoque conferido ao poder político da liberdade individual e do mercado. A liberdade de escolha do indivíduo garantiria espontaneamente a harmonia entre as posições individuais, sendo assim, a solução para os problemas da ação coletiva e para o adequado acesso aos bens produzidos; ao passo que o mercado regularia as relações sociais e limitaria a extensão política e institucional, preservando o âmbito de atuação das liberdades individuais (Babireski, 2014). O Estado dentro dessa concepção passa a ser um Estado mínimo, porém não ausente. É um Estado com burocracia reduzida, de função regulatória tanto na produção direta (estimulando a livre iniciativa e o mercado), quanto na prestação de serviços à população. O Estado planificador cede lugar ao Estado garantidor da estabilidade macroeconômica, atuando como facilitador da atividade empresarial, através de reserva de mercado, concessão de créditos para investimentos e até políticas públicas para recolocação profissional (ibidem, 2014: 24-25).

Bauman (1998) sintetiza os novos marcos conceituais em que se fundamenta a direita neoliberal. Essa direita reinterpreta o estado de bem-estar como uma caridade estatal impagável, transformando-o num estigma de incapazes e desvalidos. Antes tidas por direitos de cidadania e proteção social coletiva, as políticas públicas universalistas, a seguridade trabalhista e os dispositivos de previdência, passaram a ser 
concebidos como um sorvedouro do dinheiro dos contribuintes. Segundo o autor, nessa nova ordem "não há mais seguro coletivo contra os riscos: a tarefa de lidar com os riscos coletivamente produzidos foi privatizada" (ibidem, 1998: 52).

Esse debate é embasado por Hayek (2010) em sua clássica obra "O caminho da Servidão", na qual o autor contrapõe duas espécies de segurança com as quais os indivíduos poderiam contar, sinalizando também os limites de intervenção do Estado. $O$ $1^{\circ}$ tipo de segurança é a segurança limitada, que pode ser conquistada por todos e não constitui privilégio, nem apresenta uma restrição à liberdade de outrem. É possível garantir a todos um mínimo suficiente relativo à alimentação, habitação e vestimentas (uma renda mínima), para conservação da saúde e da capacidade de trabalho em uma sociedade que atingiu um grau geral de riqueza. Também é aceitável que o Estado auxilie num esquema abrangente de previdência social para auxiliar a recolocação profissional dos trabalhadores. Já o $2^{\circ}$ tipo de segurança - a segurança absoluta produz injustiça e perda da liberdade individual porque pretende ser a garantia de uma renda específica que se julgue que cada um mereça. A reinvindicação desse tipo de proteção aos indivíduos contra a redução de suas rendas, segundo Hayek, é inconciliável com o sistema de livre escolha das ocupações porque demandaria um planejamento excessivo (Estado autoritário) sobre o poder de escolha dos indivíduos. Em qualquer sistema no qual a distribuição dos indivíduos entre as várias ocupações e os diferentes setores da economia resulte da escolha individual, a remuneração corresponderá à utilidade dos indivíduos para os outros membros da comunidade. Aprofundando essa argumentação, Hayek conclui que as demandas dos desvalidos para que o Estado intervenha em seu favor, acarretará no aumento constante da insegurança daqueles sobre os quais recai o ônus, já que esse "privilégio" (grifo nosso) é concedido parcialmente. Em consequência, aumentará também de modo contínuo o valor atribuído ao privilégio da segurança, até que nenhum custo, nem o da própria liberdade individual, pareça excessivo.

Prosseguindo com esse autor, sua defesa do individualismo moral (ainda que pensada sobre os Estados comunistas) ajuda a ilustrar a concepção de Estado dos liberais/neoliberais. Hayek (2010) aponta que a planificação econômica (Estado 
intervencionista) consiste em determinar quais são as necessidades de cada um segundo as concepções do Estado e não dos próprios indivíduos. A planificação econômica seria totalmente oposta ao individualismo moral, uma vez que, os indivíduos almejam dinheiro porque ele os permite escolher da forma mais ampla como desfrutar dos resultados de seus esforços; não competindo ao Estado retirar essa ingerência de escolha da vida de seus cidadãos.

Uma intervenção mínima do Estado no mercado tem por um de seus principais propagadores e defensores Ludwig von Mises. Esse autor, assim como Hayek, sistematiza as bases epistemológicas para a compreensão neoliberal de Estado. Mises (2010) chama a atenção para a necessidade da existência do governo, pois sem ele seria impossível a cooperação social pacífica. Contudo, o governo é um meio para atingir o intento de manutenção da ordem social e; para o autor, todo meio é um custo. O único critério para apreciar as leis e os métodos usados para sua implementação é, portanto, verificar se são ou não eficientes para salvaguardar a ordem social que se deseja preservar. Se o governo não limita suas atividades à preservação da propriedade privada dos meios de produção e à proteção contra as tentativas de violência ou fraude e, ao contrário, interfere na atividade econômica através de ordens e proibições, o intervencionismo torna-se um custo. Como o governo usa de proibições e violência para garantir suas pretensões, quem pede maior intervenção estatal está, em última análise, pedindo mais compulsão e menos liberdade. Por isso, o Estado deve apenas se restringir ao papel para o qual foi concebido: mantenedor da ordem social e da propriedade privada. Qualquer tentativa de ingerência em outros domínios, como o econômico, configura-se uma usurpação de liberdade que não lhe é própria.

Outro marco teórico para a doutrina neoliberal foi o economista norteamericano Milton Friedman. Apoiando a postura neoliberal de predileção a um Estado mínimo, atribui-se a ele a frase: "acho que a solução do governo para um problema é usualmente tão ruim quanto o problema e muitas vezes torna o problema pior". À semelhança dos outros dois autores supracitados, Friedman (1982) também assume a importância residual do papel do Estado. Cabe nota, entretanto, sua percepção sobre a pobreza e como ela inspira as modernas políticas públicas focalizadas que os partidos 
políticos de esquerda no Brasil (e na América latina) implementaram e que a oposição de direita reconhece. $\mathrm{O}$ autor percebia a necessidade de se aliviar a extrema pobreza por meio de ações do Estado, definindo dois critérios para o desenho dessa política: 1) os programas devem ter foco no pobre e não no assalariado, no negro, pequeno fazendeiro ou qualquer outro grupo que se supõe ser menos favorecido, mas que pode não o sê-lo; 2) o programa não deve interferir no funcionamento do mercado ${ }^{5}$. A solução proposta por Friedman é a de um imposto negativo; ou seja, quem tem renda até um determinado teto, recebe um subsídio de transferência de renda direta. Essa noção influenciou a criação de programas de transferência direta de renda, como o Bolsa Família no Brasil.

Conservadorismo e neoliberalismo foram mobilizados como duas correntes norteadoras para o debate sobre as bases epistemológicas da ideologia de direita contemporaneamente. Nosso debate parte dos pressupostos trazidos pelos dois pensamentos para alocar a tipologia pretendida por esse trabalho no espectro ideológico dos partidos políticos brasileiros: um "neoliberalismo pragmático", de inclinação neoliberal e uma direita "conservadora não-elitizada". Um exame mais acurado do arcabouço teórico da literatura brasileira sobre a ideologia de direita permitirá comprovar nossa hipótese: a pertinência da díade.

\section{Debates sobre a direita na literatura brasileira}

Os partidos políticos brasileiros de direita teriam polarizado essa ideologia ao longo do tempo em dois vieses distintos - um grupo do chamado "neoliberalismo pragmático" - ilustrado pelo Partido da Social Democracia Brasileira (PSDB), Democratas (DEM) e Partido Progressista (PP), e outro grupo do "conservadorismo não-elitizado" - representado pelo Partido Renovador Trabalhista Brasileiro (PRTB), Partido da República (PR) e Partido Social Cristão (PSC); mas com pontos de interseção oriundos da mesma moral conservadora e da predileção econômica (neo)liberal.

\footnotetext{
${ }^{5}$ Por isso, a política do salário mínimo é considerada por Friedman uma solução falha. O salário é considerado um preço como qualquer outro no mercado.
} 
Esse último grupo - "conservadorismo não-elitizado" - configura um perfil de partidos ainda em consolidação no jogo político brasileiro. Partidos conservadores e de pequeno a médio porte e geralmente sem grande expressão individual, mas que fazem coligação/coalizão com bases governistas - independente do conteúdo ideológico ou pragmático dessas - tornando-se, se não o fiel da balança, um elemento relevante para a governabilidade. Apresentam as singularidades de: (1) serem partidos com relativo pouco tempo de criação, como o PR criado em $2006^{6}$; $(2)$ no qual os principais nomes dessas legendas são figuras com profissões de grande apelo às massas: pastores, radialistas, apresentadores de tv; caso dos pastores Everaldo (PSC) e Marcelo Crivela (PR); (3) não necessariamente, mas comumente, denotam valores religiosos através de seus programas partidários e/ou do discurso/personalidade de seus representantes mais importantes; explicitamente corroborados pelos três partidos (Codato; Bolognesi; Roeder, 2015; Cowan, 2014).

Esses partidos diferem-se, assim, do que chamamos de "neoliberalismo pragmático" - partidos já institucionalizados (PFL, atual DEM e PSDB remontam sua criação à 1986 e 1989, respectivamente); herdeiros políticos da Aliança Renovadora Nacional (Arena), partido de apoio à Ditadura Militar, caso do PFL; de alinhamento com a doutrina econômica liberal/neoliberal, exemplificada pela política econômica do governo de Fernando Henrique Cardoso (PSDB), com coalizão composta pelo antigo PFL (DEM); e assentados nas classes médias e elites abastadas, contemplado pelos três partidos (Alves, 2000; Carreirão, 2006).

As correntes de pensamento conservadorismo e neoliberalismo podem ser retomadas para balizar as práticas e motivações dos polos de nossa díade. Após a ascensão dos prognósticos neoliberais nos anos 1980 e 1990, um ciclo de governos de (centro)esquerda dão início nos anos 2000 a uma virada eleitoral e programática no panorama político do Brasil e da América latina, forçando uma reconfiguração da direita na região. Surge, assim, uma cisão na estratégia de ação ou possibilidade conjectural para esse espectro: constituir-se oposição a esses governos progressistas (PSDB e DEM) ou consolidar-se politicamente fazendo coalizão com a esquerda (PP e $P R)$.

\footnotetext{
${ }^{6}$ O PR é criado em 2006, mas herdando o legado dos então extintos Partido Liberal - PL e Partido da Reedificação da Ordem Nacional - PRONA.
} 
Os partidos do "neoliberalismo pragmático" possuem um discurso programático crítico às reformas e programas sociais implementados nos últimos anos pelos governos de partidos de esquerda, estabelecendo a agenda de retórica da oposição. Pregam a ortodoxia econômica, a livre iniciativa individual e no mercado, eficiência governamental e administrativa e controle do crescimento. Criticam a extensão do Welfare State como uma estratégia assistencialista e não pragmática. Assentam suas bases eleitorais na classe média e alta, defendendo a moralidade tradicional, a lei e a ordem.

Mainwaring, Power e Meneguello (2000) em seu trabalho "Partidos Conservadores no Brasil Contemporâneo" argumentam que os partidos da direita tradicional apresentam um razoável sucesso na manutenção do poder político. Desde a sua formação no Império até o fim da Ditadura Militar, esses partidos têm integrado, de forma consistente, as coalizões nacionais, conseguindo nos anos 1990, renovar suas imagens programáticas sob o signo de liberais, vinculando-se ao governo Fernando Henrique Cardoso (1994-2002). Os partidos que conseguiram se afastar da imagem de retrógrados e autoritários tenderam a obter melhor desempenho eleitoral entre os eleitores mais abastados e escolarizados, residentes das regiões economicamente desenvolvidas no país (2000: 13).

Madeira e Tarouco (2010), analisando os programas partidários do herdeiro direto da Aliança Renovadora Nacional (ARENA) - partido sustentáculo do Regime Militar (Kinzo, 1988): o Partido Democrático Social (PDS) e do posterior Partido da Frente Liberal (PFL) - atual Democratas (DEM), apontam para a necessidade de reinterpretação dos vínculos com a Ditadura. Os autores demostram que quando um determinado partido possui uma posição fortemente estabelecida e contrária a da maioria do eleitorado, seu principal interesse é o de não trazer essa questão para o debate eleitoral (2010: 13). Esse ponto corrobora o que já foi citado sobre os partidos de direita tradicional; os que conseguem melhor sobrevida na redemocratização são os que mais se afastam ou superam a associação com o período autoritário (idem, 2000).

Singer (2002) traz uma contribuição relevante para marcar as fronteiras de nossa classificação. Segundo o autor, em países de forte desigualdade social, como o 
Brasil, há sempre um espaço aberto para o surgimento de uma direita populista, que prega mudanças e, nesse sentido, não tem um discurso conservador - contrário às transformações sociais; distingue-se da esquerda pela metodologia da mudança. Enquanto a direita populista quer reforçar a autoridade do Estado, na expectativa de que mudanças se deem "de cima para baixo", sem risco de instabilidade social, a esquerda prega uma mudança com base social participativa (2002: 60). Fernando Collor na eleição presidencial de 1989, com seu discurso "reformista moderado", ilustra o limiar entre o que estamos parametrizando em cada uma de nossas tipologias de direita. Esse candidato propunha uma reforma do Estado para aumentar a eficiência da máquina pública e reduzir a corrupção e a incompetência, numa construção tipicamente da direita neoliberal ("neoliberalismo pragmático"), que identifica no Estado a causa dos males sociais. No entanto, o caráter propriamente conservador de sua candidatura, ao preservar a ordem e reforçar a autoridade do Estado como executor de sua auto-reforma (paradoxalmente, a autoridade do próprio Estado que ele atacava), aproxima-se das posições percebidas pelo "conservadorismo nãoelitizado".

Essa direita mais recente conflui em diversos aspectos com seu corolário, porém incorpora agendas da esquerda e do centro. Defende o capitalismo como modelo econômico (principalmente o neoliberalismo) e os preceitos morais tradicionais; ao mesmo tempo, aceita e se vale das vantagens políticas (e eleitorais) dos programas sociais implementados pela esquerda, reforçando, ainda, a sua desvinculação com a memória do regime ditatorial (Codato; Bolognesi; Roeder, 2015); ou seja, o conservadorismo não-elitizado "constrói-se em torno de uma tradição conservadora no âmbito social, com preferência por regimes políticos com sentido de autoridade e não autoritários, continua desconfiando das massas e vem buscando ser competitivo eleitoral e politicamente" (Babireski, 2014: 26) e dentre seus eleitores e parlamentares, destacam-se grupos demográficos não-econômicos como religiosos e militares.

Alves (2000), através de surveys ${ }^{7}$ realizados com o eleitorado da cidade de São Paulo, sugere como inventário dos conteúdos ideológicos da nova direita uma agenda

\footnotetext{
${ }^{7}$ A mesma metodologia de surveys é utilizada por Bohn (2004) para ratificar posições conservadoras nas denominações religiosas do chamado "conservadorismo não-eliitizado"; principalmente, evangélicos neopentecostais. Posições reativas ao aborto, à homossexualidade masculina, ao casamento
} 
popular e conservadora nas questões morais, e autoritária na forma de ver a política. Correligionário das medidas neoliberais de privatização e desregulamentação, esse perfil político apresentou-se tolerante às desigualdades sociais, mas inflexível em domínios morais como aborto, homossexualidade e família, ainda que esses dados tenham sido pouco significativos na pesquisa. Com esses resultados, a autora também contribui para a nossa hipótese da existência de "duas direitas":

\begin{abstract}
Com base nos dados de 1993, sobre o comportamento eleitoral em 1989, constatamos a "pluralidade" da direita. Há uma direita mais ideológica, mais politizada, que defende os interesses do laissez-faire, que não assume totalmente o rótulo "direita", mas que é no mínimo anti-esquerda, em geral identificada com as classes mais altas. Esta direita esteve associada ao voto em Paulo Maluf no primeiro turno. Há uma direita mais populista, personalista, que mobilizada apoio pelo viés apolítico dos temas da moralidade e pelas formas autoritárias de agir no espaço político, geralmente encontrando suas bases nas classes mais baixas (Alves, 2000, pp.221-222).
\end{abstract}

Cowan (2014) mostra que o moralismo identificado por Alves (2000) tem bases religiosas. Historicamente auto identificados como apolíticos, os evangélicos no Brasil evitaram inicialmente envolvimento político, mas a partir do momento em que o país começa a reconstruir suas instituições democráticas, nas décadas de 1970 e 1980, protestantes de várias denominações começaram a eclodir na cena política. Foram delineando-se, assim, dois grupos de lideranças: os progressistas que pregavam pluralidade, democracia e equidade e; os que pavimentaram a base da direita evangélica - conservadorismo não-elitizado - uma combinação reativa a um suposto conflito moral e cultural que o momento de ruptura de regime promovia na sociedade (ibidem, 2014: 105). O último grupo foi estabelecendo, ao longo de anos de pronunciamentos públicos com suas bases, a necessidade da atuação na política. Já na década de 1980, essas lideranças passaram a apoiar publicamente os governos militares, principalmente o do presidente João Baptista Figueiredo (1979-1985), dando início a um projeto de institucionalização política do conservadorismo evangélico (ibidem, 2014); projeto esse que só tendeu a se consolidar, como ilustra a chamada

homoafetivo e à realização de greves, mas favoráveis à intervenção do Estado nos domínios econômicos, apresentam resultados semelhantes aos encontrados por Alves (2000). 
Bancada Evangélica na Câmara dos Deputados, composta, na $52^{\circ}$ Legislatura (20032007), por 54 membros: 28 pastores e 26 deputados autodeclarados evangélicos (Rodrigues, 2009).

Sung (2015) aprofunda essa tese da rigidez moral dos evangélicos (em especial, os neopentecostais constituintes do conservadorismo não-elitizado), argumentando que a teologia da prosperidade ${ }^{8}$ - principal corrente teológica seguida por essas agremiações - indica que a chave do progresso material é a obediência aos mandamentos de Deus e que o hedonismo, principalmente ligado à homossexualidade (entendido por esses grupos como um desvio das relações sexuais tradicionais), é o resultado do afastamento do mundo moderno de Deus, isto é, a desobediência aos mandamentos de Deus. Nas palavras do autor:

E qual é o grande pecado do mundo hoje? Não pode ser o consumismo ou o capitalismo, como critica a teologia da libertação, porque isso seria negar o desejo de participar do consumo e a própria noção de prosperidade como benção. Também não pode ser a injustiça social, porque isso seria criticar o discernimento de Deus na distribuição das bênçãos. Nessa lógica, os pobres que não melhoram sua situação econômica são culpados por não aceitarem Jesus e não seguirem a Palavra de Deus. A mira então se volta ao hedonismo do mundo (Sung, 2015, p.49).

Esse discurso moralista e conflitivo de viés religioso também é apontado por Peirucci (1999), como o traz Babireski (2014):

[...] as bases populares da direita política tendencialmente radical costuram seu consenso ideológico sob a predominância folgada de dois campos semânticos, estruturados em torno de dois motivos antiliberais: a reação antiliberalizante em moral familiar e a demanda antiliberal de maior

\footnotetext{
${ }^{8}$ A Teologia da Prosperidade foi disseminada no Brasil a partir do final da década de 1970 com o surgimento das igrejas neopentecostais e desde então, tem ganhado cada vez mais adeptos em todas as camadas sociais. Sua forma de abordagem da Bíblia e de vivência da religião rompe com a ética protestante presente no protestantismo histórico e até mesmo com temas comuns às religiões cristãs, como a caridade, a salvação e a rejeição dos prazeres do mundo. Segundo essa doutrina, o pagamento do dízimo tornou-se um dogma obrigatório, sem o qual o fiel jamais poderá ser abençoado. Os pregadores se posicionam como profetas, homens de Deus. Na elaboração do discurso da prosperidade, há uma clara hierarquização entre emissor - o ungido - e o ouvinte - necessitado de bênçãos. Por outro lado, com o abandono da pregação apocalíptica e do fim do mundo, a TP gera uma conformação ao mundo e adequação ao modo de vida secular, sem, porém, ser desencantada. Ficar rico está ao alcance de qualquer pessoa, mas isto só será possível se a igreja estiver recebendo contribuições financeiras; para isso há uma lógica discursiva que objetiva convencer o fiel de que ele não poderá prosperar sem isso. As falas dos pastores falam de semear (a lógica camponesa) e investir (lógica empresarial) e elas estão impregnadas também de uma historicidade, da lógica neoliberal e individualista, a pobreza é falta de fé, é desobediência à igreja, portanto, é responsabilidade de quem está nessa condição. Através da TP o neopetencostalismo legitima e naturaliza a concentração de renda e a ausência ou precariedade das políticas sociais. (Sousa, 2011: 243-244).
} 
intervencionismo do Estado na economia. (Pierucci, 1999 apud Babireski, 2014, p.28).

A premência da intervenção do Estado na economia e de um Estado promotor de políticas públicas justifica-se pelo fato dessa direita religiosa (sobretudo, evangélica) decorrer de escolhas feitas pelos mais pobres ${ }^{9}$ : setores sociais e espaços geográficos de extensa precariedade de condições e que, portanto, revelam uma completa ausência do poder público, e consequentemente, uma enorme demanda por ele (Bohn, 2004).

Retomando, por fim, à famosa definição de esquerda e direita cunhada por Bobbio (2011), enquanto a "nova direita" primaria pela manutenção do status quo, através de políticas para alcançar a igualdade que favorecem os já ricos (desregulamentação dos mercados, incentivos à produtividade empresarial, etc), o "conservadorismo não-elitizado" reconhece que não é possível governar desconsiderando os socialmente excluídos, principalmente por seu representativo peso eleitoral. Não perseguem a igualdade plena preterida pela esquerda, nem se contentam com a defesa de uma desigualdade inevitável feita pela direita tradicional; estabelecem um pacto de igualdade de possibilidades. Em outras palavras, essa igualdade pode ser traduzida no acesso às condições materiais de bens de consumo no mercado.

\section{Considerações finais}

A operacionalização do conceito de direita, especialmente como identificação ideológica dos partidos políticos brasileiros, é uma discussão passível de questionamentos e fonte de dissenso entre os próprios estudiosos dessa temática. Uma revisão da literatura internacional e nacional sobre os conceitos perfilhadores e interpelados pela direita permitiu apontarmos para a configuração orgânica de um conjunto de valores compartilhados por essa ideologia. A defesa de princípios

\footnotetext{
${ }^{9}$ Nesse mesmo trabalho, Simone Bohn (2004) contradiz uma inclinação comum em pensar que o pertencimento à uma religião no Brasil seria uma opção dos estratos sociais de baixa renda. Pelo contrário; os dados trazidos por ela mostram que $59,7 \%$ das pessoas sem vínculo religioso pertencem aos dois segmentos mais carentes da sociedade (ibidem: 298).
} 
conservadores universais como defesa dos valores da família tradicional - patriarcal e heteronormativa - e das limitações impostas à liberdade pessoal, consagradas pela moral meritocrática e pelo ideal de prosperidade individual (self-made man) são posicionamentos políticos constituintes do espectro da direita. A intensidade das preferências e práticas políticas e discursivas num contínuo neoliberal-conservador representam a validade da bifurcação apontada na direita por esse trabalho: "neoliberalismo pragmático" de inclinação majoritariamente neoliberal e "conservadorismo não-elitizado" de tendência conservadora e religiosa.

\section{Referências bibliográficas}

Alves, Maria Teresa Gonzaga. 2000. "Conteúdos ideológicos da nova direita no município de São Paulo: análise de surveys". Opinião Pública, vol. 6, n. 2, pp. 187-225.

Amorim Neto, Octávio. 2011. De Dutra a Lula. Rio de Janeiro: Elsevier.

Babireski, Flávia. 2014. A direita no Brasil, Chile e Uruguai: estudos dos programas e manifestos partidários. Dissertação apresentada à Universidade Federal do Paraná para a obtenção do grau de Mestre em Ciência Política.

Bauman, Zyygmunt. 1998. "Os estranhos da era do consumo: do estado de bem-estar à prisão". In: Bauman, Zyygmunt. O Mal-estar da Pós-modernidade. Rio de Janeiro: Zahar, pp. 4961.

Bobbio, Norberto. 2010. "Teoria das Elites". In: Bobbio, Norberto; Matteucci, Nicola; Pasquino, Gianfranco (orgs.). Dicionário de Política. 13.ed. Brasília: Unb, 2010, pp. 242-246.

Bobbio, Norberto. 2011. Direita e esquerda: Razões e significados para uma distinção política. São Paulo: UNESP.

Bonazzi, Tiziano. 2010. "Conservadorismo". In: Bobbio, Norberto; Matteucci, Nicola; Pasquino, Gianfranco (org.). Dicionário de Política. 13 ed. Brasília: Unb, pp. 242-246.

Carreirão, Yan. 2006. "Ideologia e partidos políticos: um estudo sobre coligações em Santa Catarina". Opinião Pública, vol. 12, no 1, pp. 136-163.

Codato, Adriano; Bolognesi, Bruno; Roeder, Karolina Mattos. 2015. "A nova direita brasileira: uma análise da dinâmica partidária e eleitoral do campo conservador". In: Velasco e Cruz, Sebastião; Kaysel, André; Codas, Gustavo (orgs.). Direita, volver ! O retorno da direita e o ciclo político brasileiro. São Paulo: Fundação Perseu Abramo, pp. 115-143.

Cowan, Benjamin. 2014. "'Nosso Terreno' crise moral, política evangélica e a formação da 'Nova Direita' brasileira”. Varia História, vol. 30, n. 52.

Downs, Anthony. 1999. Uma teoria econômica da democracia. São Paulo: Edusp. 
Ennser, Laurenz. 2010. "The homogeneity of West European party families: the radical right in comparative perspective". Party Politics, v.18, n.2, pp. 151-171.

Fernandes, Luís. 1995. “Muito barulho por nada?” Dados, v. 38, n. 1, pp. 107-143.

Figueiredo, Argelina \& Limongi, Fernando. 1999. Executivo e Legislativo na Nova Ordem Constitucional. Rio de Janeiro: FGV.

Fleischer, David. 2007. "Os partidos políticos". In: Avelar, Lúcia \& Cintra, Antônio Octávio. Sistema político brasileiro: uma introdução. São Paulo: Editora Unesp, pp. 303-348.

Friedman, Milton. 1982. Capitalismo e liberdade. São Paulo: Nova Cultura, Coleção Os Economistas.

González, Andrea. 2013. "Continuidad y cambio de los partidos de derecha chilenos: las dos almas de la derecha chilena". VII Congreso de la Asociación Latinoamericana de Ciencia Política (ALACIP), Bogotá, Colombia.

Guiot, André Pereira. 2010. "A construção da ideologia neoliberal no PSDB (1988-1994)". Encontro Regional da Anpuh-Rio: memória e patrimônio, 14. Rio de Janeiro. Disponível em: http://www.encontro2010.rj.anpuh.org/resources/anais/8/1276606395_ARQUIVO_Aconstruca odaideologianeoliberalnoPSDB_1988-1994_.pdf. Acesso em: 4 maio 2016.

Hayek, Friedrich. 2010. O caminho da servidão. 6.ed. São Paulo: Instituto Ludwig von Mises Brasil.

Kinzo, Maria. 1988. Oposição e autoritarismo: gênese e trajetória do MDB (1966-1979). São Paulo: Vértice, Editora Revista dos Tribunais.

Kinzo, Maria. 1990. "O quadro partidário e a constituinte". In: Lamounier, Bolivar. (org.) De Geisel a Collor: o balanço da transição. São Paulo: IDESP / Sumaré.

Kirk, Russel. 2005. The Conservative Mind. Alabama: Alabama Policy Institute.

Mainwaring, Scott; Power, Timothy; Meneguello, Rachel. 2000. Partidos conservadores no Brasil contemporâneo: quais são, o que defendem, quais são suas bases. São Paulo: Paz e Terra.

Manin, Bernard. 1995. "As Metamorfoses do Governo Representativo". Revista Brasileira de Ciências Sociais, no 29, pp. 5-34.

Mayer, Rodrigo \& Babireski, Flávia. 2013. "As diferenças dos principais partidos de direita: um estudo sobre Brasil e Chile". IV Seminário Nacional Sociologia \& Política. Curitiba: UFPR.

Mercadante, Paulo. 1980. A consciência conservadora no Brasil. 3.ed. Rio de Janeiro: Nova Fronteira.

Mises, Luwig von. 2010. Ação Humana: um tratado de economia. 3.ed. São Paulo: Instituto Ludwig von Mises Brasil.

Novaes, Carlos Alberto Marques. 1994. "Dinâmica institucional da representação: individualismo e partidos na Câmara dos Deputados". Novos Estudos, n. 38, pp. 99-147. 
Oliveira, Tatiana \& Benetti, Pedro. 2014. "As novas direitas sul-americanas: Análise das experiências chilena e colombiana". Observador On-line, v. 9, n.1. Disponível em: <http://www.opsa.com.br/images/pdf/observador/Observador_OPSA_vol_9_n_1 _2014_Oliveira_e_Benetti.pdf> Acesso em: 11 de maio de 2016.

Partido da República. Manifesto do Partido da República. 2006. Disponível em: http://www.partidodarepublica.org.br/partido/manifesto.html. Acesso em: 05 jul. 2016.

Partido da República. PL e PRONA promovem fusão. Disponível em: http://www.partidodarepublica.org.br/partido/historia_do_pr.html. Acesso em: 05 jul. 2016.

Partido Social Cristão. Histórico. Disponível em: http://www.psc.org.br/site/partido-socialcristao/historico.html. Acesso em: 05 jul. 2016.

Pierucci, Antônio Flávio. 1999. Ciladas da diferença. 1.ed. São Paulo: Editora 34.

Piven, Frances Fox. 1992. Labor Parties in postindustrial societies. New York: Oxford.

Power, Timothy. 2000. The Political Right in Postauthoritarian Brazil: Elites, institutions, and democratization. University Park: Pennsylvania State University.

Rodrigues, Leôncio. 2009. Mudanças na classe política brasileira. Rio de Janeiro: Centro Edelstein de Pesquisas Sociais.

Rodrigues, Leôncio. 2002. Partidos, ideologia e composição social. São Paulo: Edusp.

Singer, André. 2002. Esquerda e direita no eleitorado brasileiro: a identificação ideológica nas disputas presidenciais de 1989 e 1994. São Paulo: Edusp.

Sung, Jung Mo. 2015. "Prosperidade sim, família homossexual, não! A nova classe média evangélica". Psicologia USP, vol. 26, n.1, pp. 43-51.

Tarouco, Gabriela \& Madeira, Rafael. 2010. "A 'direita envergonhada' no Brasil: como partidos reinterpretam seus vínculos com o regime militar?" $V$ Congresso Latino-americano de Ciência Política, ALACIP.

Tarouco, Gabriela \& Madeira, Rafael. 2013. "Partidos, Programas e o Debate sobre esquerda e direita no Brasil”. Sociologia Política, vol. 21, n. 45, pp. 149-165. 